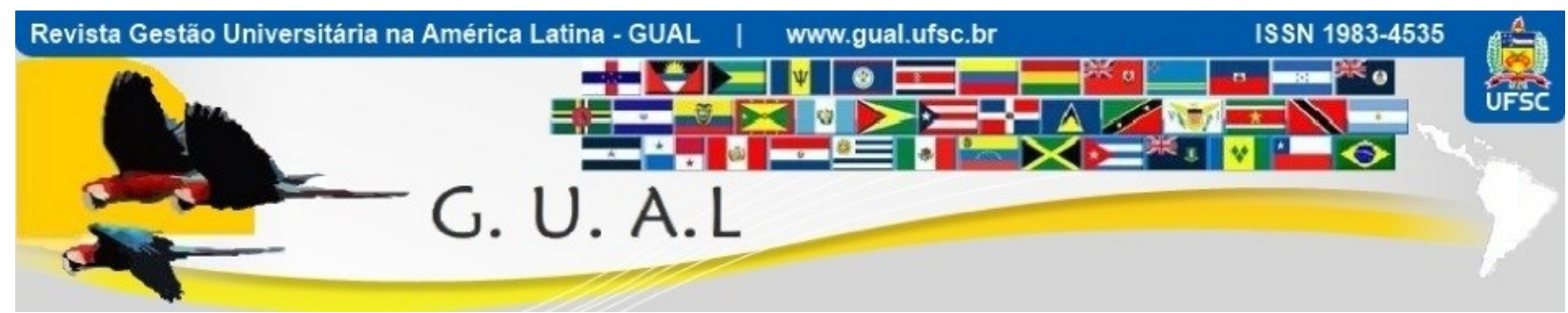

DOI: http://dx.doi.org/10.5007/1983-4535.2018v11n3p122

\title{
INTENÇÃO EM INGRESSAR NO ENSINO SUPERIOR: UMA ANÁLISE SOB A PERSPECTIVA DOS VALORES E DOS FATORES MOTIVACIONAIS
}

\author{
INTENTION TO ENTER HIGHER EDUCATION: AN ANALYSIS FROM THE \\ PERSPECTIVE OF VALUES AND MOTIVATIONAL FACTORS
}

Fernando Lopes Coutinho, Graduado

Pontifícia Universidade Católica de Minas Gerais - PUC Minas

fernandocout@gmail.com

Ramon Silva Leite, Doutor Pontifícia Universidade Católica de Minas Gerais - PUC Minas ramons1@pucminas.br

Sebastião Aleixo Souza Filho, Mestre Pontifícia Universidade Católica de Minas Gerais - PUC Minas tiao.aguia@gmail.com

Recebido em 20/janeiro/2017

Aprovado em 06/abril/2018

Sistema de Avaliação: Double Blind Review

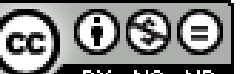

EY NC ND Esta obra está sob uma Licença Creative Commons Atribuição-Uso. 


\title{
RESUMO
}

O percentual da população brasileira com ensino superior ainda é baixo, mesmo quando se compara com outros países da América Latina. Assim, compreender as influências e motivações dos alunos do ensino médio para ingressarem no ensino superior se torna relevante. $\mathrm{O}$ presente estudo objetivou analisar quais fatores influenciam os alunos do ensino médio no reconhecimento da necessidade de cursar o ensino superior. Buscou-se entender também a influência das condições socioeconômicas e da natureza administrativa das instituições frequentadas pelos alunos (públicas ou privadas) nesta intenção, assim como o papel dos valores pessoais nessa pretensão. A pesquisa, de natureza quantitativa descritiva, baseou-se em uma survey e contou com a participação de 406 alunos regularmente matriculados no terceiro ano do ensino médio. Os dados foram tratados por meio de estatísticas descritivas e testes de comparação de médias entre grupos. Os resultados indicaram que, no reconhecimento da necessidade de ingressarem no ensino superior, os alunos sofrem, individualmente, influência tanto de sua situação socioeconômica, quanto de fatores intrínsecos e extrínsecos, bem como de seus valores individuais e sociais. Observou-se diferenças de valores entre os alunos, de acordo com o tipo de instituição escolar frequentada, inexistindo diferença quando a comparação é feita entre os grupos de pretensão.

Palavras chave: Ensino Superior. Intenção em ingressar. Valores Pessoais.

\begin{abstract}
The percentage of the Brazilian population with higher education is still low, even when it's compared with other Latin American countries. Thus, it's relevant to understand the influences and motivations of high school students to enter higher education. The present study aimed to analyze which factors influence high school students in the recognition of the need to attend higher education. It was also sought to understand the influence of the socioeconomic conditions and the administrative nature of the institutions attended by the students (public or private) for this purpose, as well as the role of personal values in this pretension. The quantitative descriptive research was based on a survey and had the participation of 406 students regularly enrolled in the third year of high school. The data were treated with descriptive statistics and t-tests comparing means between groups. The results indicated that, in recognition of the need to enter higher education, students are individually influenced by their socioeconomic situation, intrinsic and extrinsic factors, as well as their individual and social values. Differences of personal values among students were observed, according to the type of school attended, and there is no difference when the comparison is made among the pretension groups.
\end{abstract}

KEY-WORDS: Higher Education. Intention to enter. Personal Values. 


\section{INTRODUÇÃO}

Embora as instituições de ensino superior existam no Brasil desde 1808, foi somente na década de 1930, com a Reforma Francisco Campos e com a criação do Ministério da Educação (MEC), que ocorreu o processo de regulamentação das universidades (MARTINS, 2002). Essas ações impactaram profunda e positivamente o ensino superior no Brasil ao longo dos anos, fazendo com que o número de matrículas chegasse a 1,4 milhão, no final da década de 1980, e superasse a casa dos 4,5 milhões em 2007. Essa ascensão de matrículas foi acompanhada pelo crescimento das Instituições de Ensino Superior (IES). Segundo o censo realizado pelo INEP (2015), no ano de 1980 havia 882 IES no país, chegando a 2.281 IES em 2007. E o crescimento não parou por aí. Pelos dados do censo de 2015 , feito pelo Instituto Nacional de Estudos e Pesquisas "Anísio Teixeira" (INEP), há mais de 8 milhões de alunos matriculados nos 33.000 cursos de graduação, espalhados pelas 2.364 IES instaladas por todo o território nacional.

Esse crescimento está atrelado à última reforma no ensino superior do país, ocorrida durante o primeiro governo Lula - entre 2003 e 2006, quando houve a aprovação do Programa Universidade Para Todos - PROUNI, pelo qual o governo concederia bolsas de estudo em IES privadas a alunos carentes, bem como ao aumento da população jovem adulta, às exigências do mercado de trabalho, ao aumento do número de concluintes do ensino médio, aos baixos níveis históricos de penetração do ensino superior no Brasil, a maior disponibilidade de financiamento estudantil e à desregulamentação do setor (SÉCCA e SOUZA, 2009).

Entretanto, afora todos estes aspectos objetivos apresentados, questiona-se o que faz com que esse grande contingente de jovens busque, no ensino superior, o direcionamento para suas vidas, sendo esta uma decisão complexa, com significativas consequências no futuro desse público. Frente a esse questionamento, deve-se levar em consideração que nossas tomadas de decisão estão permeadas por nossos valores. Conforme expressa Schwartz (2011), quando pensamos em valores e, particularmente, nos nossos valores, associamos ao que temos de importante nas nossas vidas, designadamente a conceitos como segurança, independência, sucesso, prazer ou mesmo sabedoria ou amabilidade. Nesta perspectiva, Tinoco, Assêncio, João e Claro (2010) lembram que cada indivíduo é detentor de um conjunto de valores pessoais, sendo que eles variam em grau e importância, razão pela qual um valor em 
particular pode ser fundamental para a existência de uma pessoa e ser dispensável para outra. Os valores podem expressar os sentimentos e o propósito na vida das pessoas.

Como apregoam Torres, Schwartz e Nascimento (2015), diversos teóricos, como sociólogos (p.e., Williams, 1968) e antropólogos (Kluckhohn, 1951) já entendiam os valores como critérios que as pessoas usam para avaliar suas ações, outras pessoas e eventos, sendo que, na psicologia, a teoria de valores humanos básicos de Schwartz (1992) tem sido um marco na compreensão deste fenômeno.

Tamayo e Schwartz (1993) afirmam que o poder motivacional dos valores tem intrigado numerosos pensadores e pesquisadores ao longo do tempo, lembrando, ainda, que as opiniões relativas a este problema variam grandemente entre os filósofos, indo desde a posição platônica (Platão, 1943) que identifica os valores com o absoluto (o Bem) até o enraizamento dos mesmos no desejo humano (Ehrenfels, 1890; Lavelle, 1951; 1955).

Considerando-se que os valores seriam importantes nas tomadas de decisões dos indivíduos, surge o questionamento que norteou a presente pesquisa: quais fatores influenciam os alunos do ensino médio no reconhecimento da necessidade de cursar o ensino superior?

Analisar esses fatores influenciadores se torna o objetivo precípuo do estudo em tela. O trabalho busca ainda: (a) verificar a influência das condições socioeconômicas na intenção de cursar o ensino superior; (b) identificar as diferenças nos valores pessoais e fatores influenciadores entre os alunos de escolas públicas e os alunos de escolas privadas; e (c) indicar as diferenças nos valores pessoais dos alunos que pretendem e não pretendem ingressar no ensino superior.

Espera-se que, com esse trabalho, se abram novas perspectivas de atuação tanto das IES, no que se refere à elaboração de estratégias condizentes com as necessidades, motivações, valores e perfil socioeconômico desse público, quanto do Poder Público, no que se refere à implementação de políticas públicas salutares, que fortaleçam o ensino superior no Brasil, trazendo, assim, perspectivas positivas aos jovens que desejam nele ingressar.

Por oportuno, informa-se que este artigo está estruturado em cinco seções, a começar desta introdução, passando, em sequência, pela fundamentação teórica; metodologia; análise de resultados; e conclusão. 


\section{VALORES PESSOAIS E COMPORTAMENTO DO CONSUMIDOR}

O processo de decisão de compra do consumidor pode ser dividido em sete etapas, das quais a primeira é o reconhecimento da necessidade, que é a raiz do consumo, o estágio em que o consumidor assume a imprescindibilidade de um bem (ou serviço) em sua vida e se predispõe a obtê-lo (BLACKWELL, MINIARD e ANGEL, 2005). Os autores afirmam também que o reconhecimento da necessidade pode surgir na alteração tanto do estado atual quanto do estado desejado. Fletcher (1988, p. 59) explica que o estado desejado é resultado da aprendizagem passada, experiência e informações obtidas sobre o que é possível e sobre as consequências das ações. Já no estado atual o reconhecimento da necessidade é disparado pela antecipação de uma necessidade, que resulta na alteração da situação corrente (BLACKWELL, MINIARD, ENGEL, 2005, p. 104).

Diante desse cenário, Bruner e Pomazal (2013) apresentam o diagrama do processo de reconhecimento da necessidade, explicando que todo o processo de reconhecimento da necessidade tem origem nos fatores influenciadores, pois eles estariam alterando a percepção do consumidor sobre seu estado atual e seu estado desejado. Segundo os autores, estes fatores seriam: (a) fatores externos - grupos de referência, cultura/classe social, características familiares, esforços de marketing e novidades; (b) fatores individuais - situação atual, pensamento/reflexão, falta de sortimento, incitação das necessidades, avaliação pós-compra, decisões anteriores e desenvolvimento individual; e (c) fatores econômicos - considerações financeiras e insuficiência de recursos. Outros autores, como Blackwell et al. (2005); Karsaklian (2000); Kotler e Keller (2006); e Giglio (2003) também elaboraram suas divisões, ficando evidente em todos que os fatores individuais, ambientais e econômicos são importantes influenciadores da percepção do consumidor sobre seu estado atual e seu estado desejado.

Todos esses fatores, no entanto, não se encontram a esmo no comportamento do consumidor. Eles são permeados - e, até, limitados - pelos valores pessoais do indivíduo. De acordo Blackwell et al. (2005), os valores representam três requisitos universais da existência humana: necessidades biológicas, requisitos de interações sociais coordenadas e demandas pela sobrevivência e funcionamento do grupo. Ainda de acordo com os autores, os valores pessoais refletem-se nas escolhas que um indivíduo faz a partir de uma variedade de valores sociais ou sistema de valores a que esse indivíduo está exposto (p.223). 
Rokeach (1973) entende valor como uma crença duradoura que, de um modo específico de conduta ou estado final de existência, é pessoal ou socialmente preferível a um modo oposto ou alternativo de conduta ou estado final de existência. Logo, os valores de uma pessoa devem permitir predizer como ela se comportará em situações experimentais e em situações da vida real. Como os valores representam as crenças sobre estados de existência desejáveis e sobre modos de comportamentos, eles influenciam também a ideia de uma pessoa sobre qual o estado desejado das coisas, assim como o modo como irão avaliar as opções disponíveis (CALVOSA, 2012).

Ainda segundo Calvosa (2012), a pesquisa do tema valores passa pelo estudo de três dimensões distintas: valores pessoais, valores laborais e valores organizacionais (TAMAYO, 2007), distinguindo-se os valores pessoais como metas ou critérios que são organizados pelos indivíduos pelo grau de importância que, independentemente da situação, servem como princípios norteadores de sua vida; valores esses que têm sido utilizados para explicar o comportamento das pessoas, suas ações e as mudanças da sociedade, além de diferenciar grupos.

Nesta visão histórica, embora, de acordo com Torres, Schwartz e Nascimento (2015), o interesse pelos valores tenha aumentado a compreensão sobre o tema, a definição do conceito não tem sido tarefa muito fácil. Atualmente há uma concordância na área em relação ao estudo dos valores do ponto de vista do indivíduo que avalia o seu meio. Sendo assim, esforços têm sido feitos no sentido de se mensurar as prioridades valorativas dos indivíduos, para compreensão das motivações subjacentes às respostas emitidas pelos mesmos em função das demandas ambientais (Schwartz, 1992).

Tamayo e Schwartz (1993) ponderam que Lavelle (1951; 1955) coloca de forma mais explícita e sistemática o aspecto motivacional dos valores, ao salientar suas dimensões seletiva e orientadora, assim como sua relação com os desejos e as necessidades do indivíduo.

É importante salientar que a discussão sobre os valores pessoais não pode se pautar sobre uma lista de valores, mas, sim, sobre um sistema de valores identificados e hierarquizados pelo indivíduo, a partir de um instrumento de medição testado e validado, que possa apresentar um escopo de valores universais (SCHWARTZ, 1992; 2011). Conforme argumenta Calvosa (2012), um sistema de valores indica preferências, diferenciando o que é prioritário do que é secundário. Essa hierarquização está relacionada com o desenvolvimento histórico-temporal, com o desejo e com o esforço para agir do indivíduo (TAMAYO, 2007). 
Em um sistema de valores, esses são priorizados em uma pessoa a partir da intensidade com que ocorrem e do desejo do indivíduo.

De acordo com Tamayo e Schwartz (1993), esses fatores preexistem ao indivíduo, sendo constituídos por (1) necessidades biológicas do organismo; (2) necessidades sociais relativas à regulação das interações interpessoais; e (3) necessidades sócio-institucionais referentes à sobrevivência e bem-estar dos grupos.

Dentro desta mesma linha de pensamento, Calvosa (2012) argumenta que, segundo Rokeach (1973), um sistema de valores é uma organização duradoura de princípios e regras, apreendida pelo ser humano, que lhe possibilita escolher entre diferentes alternativas, resolver conflitos e tomar decisões, constituindo-se uma hierarquia de valores, uma classificação ordenada de valores ao longo de um contínuo de importância; hierarquia essa baseada na maior ou na menor importância que os valores têm na vida do indivíduo (TAMAYO; SCHWARTZ, 1993; ROKEACH, 1973; TAMAYO, 2007).

Assim, a organização hierárquica de valores pressupõe que o indivíduo se relaciona com o mundo físico e social como ator que participa, toma partido e se envolve. Os valores implicam em preferência e distinção entre o que é significativo para o indivíduo e o que é secundário, entre o que tem importância e o que não tem (CASTRO, CALVOSA, WRIGHT e CASADO, 2009).

Calvosa (2012), citando Tamayo (2007), expressa que o SVS - Schwartz Value Survey (Inventário de Valores de Schwartz) evidencia que o autor aborda, de forma relativamente completa, valores universais, culturais e o sistema estruturado sob os quais esses valores se inter-relacionam. O próprio Schwartz $(1992 ; 2011)$ justifica a superioridade da forma de mensuração com base em avaliação intervalar de importância, pois permite ao pesquisador coletar em menos tempo uma lista mais longa de valores e capturar dados com notas negativas a certos valores e aos respondentes relacionar valores que julguem igualmente importantes (CASTRO et al., 2009).

Uma comprovada desvantagem do SVS está no nível de abstração que, pressupõe-se, tenha o participante. Por isso, não se pode empregar o SVS em amostras intelectualmente muito heterogêneas. Para minimizar esse desconforto, Schwartz desenvolveu um segundo instrumento de mensuração de valores. Para efetuar amostras com pessoas de áreas rurais, de países em desenvolvimento, indivíduos que não tiveram oportunidades de estudar em escolas 
ocidentais, além de crianças e adolescentes, o autor desenvolveu um novo instrumento denominado Perfil de Valores Pessoais - PVQ (SCHWARTZ, 2011).

Tanto o SVS quanto o PVQ são instrumentos igualmente válidos e confiáveis, dando aos pesquisadores a disponibilidade de escolha para medir valores pessoais (ROCCAS, SCHWARTZ e AMIT, 2010), contudo, indubitavelmente, a teoria de valores humanos básicos de Schwartz (1992) é aquela que tem ganhado maior atenção dos pesquisadores da área.

Schwartz (1992) considera os valores como um requisito universal da existência humana e, ao propor a teoria, provocou a mudança do mero estudo de uma lista de valores para o desenvolvimento de conjuntos de metas motivacionais, capazes de predizer diversas variáveis em diferentes grupos culturais. Importante destacar a ressalva de Tamayo e Schwartz (1993), ao observarem que, dentro dessa matriz motivacional, os valores relacionam-se entre si de forma dinâmica. Assim, os valores a serviço de interesses individuais são opostos àqueles que servem a interesses coletivos, podendo-se, pois, postular dois tipos básicos de relacionamento entre eles: de compatibilidade e de conflito.

Sambiase, Teixeira, Bilsky, Araújo e Domenico (2014) apresentam a estrutura dos valores desenvolvidos por Schwartz, com as quatro dimensões que eles formam, podendo ser usados para determinar o perfil do consumidor, compreendendo se seu comportamento seria voltado para a: (a) autopromoção, que seria um comportamento individualista; (b) autotranscendência, comportamento que se preocupa com o bem-estar das pessoas; (c) conservadorismo, se apegando ao tradicional, regrado e seguro; ou (d) aberto a mudanças, em que o comportamento se voltaria em busca do prazer, do novo e do variado. A Figura 1, a seguir, apresenta visualmente essa estrutura. 
Figura 1 Estrutura motivacional dos valores

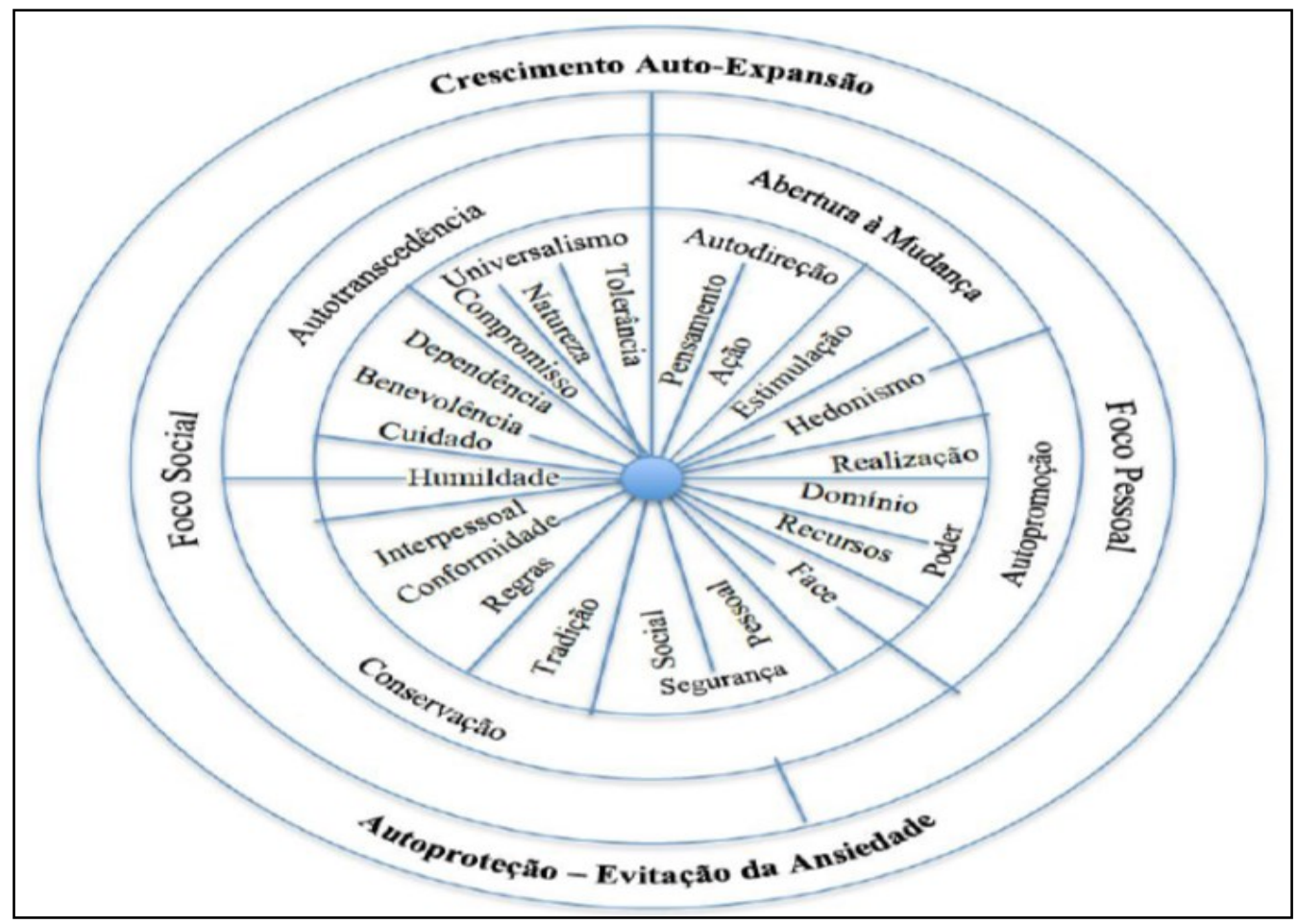

Fonte: Torres, Schwartz e Nascimento (2015).

Para Schwartz (1992), citado por Torres, Schwartz e Nascimento (2015), os valores humanos podem ser definidos como (1) crenças ligadas à emoção de forma intrínseca que, quando ativadas, geram sentimentos positivos e negativos; (2) um construto motivacional que orienta pessoas para agirem de forma adequada; (3) transcendem situações e ações específicas, diferindo das atitudes e normas sociais, além de orientar as pessoas em diversos contextos sociais; (4) guiam a seleção e avaliação de ações, políticas, pessoas e eventos e compõem critérios para julgamentos; e (5) ordenam-se de acordo com a importância relativa dada aos demais valores, formando um sistema ordenado de prioridades axiológicas.

Assim, ainda de acordo com Torres e Nascimento (2015), tendo como base esta definição, Schwartz (1992) propôs uma teoria unificadora dos valores humanos, a qual prevê uma estrutura dinâmica entre as categorias motivacionais dos valores, de forma que os indivíduos apresentem alta prioridade para os tipos compatíveis e baixa prioridade para tipos conflitivos.

Dessa forma, a prioridade dos tipos motivacionais não se estabelece de forma aleatória, mas de forma consistente com os domínios motivacionais. Concebidos desta forma, os valores humanos são construtos importantes no conjunto dos conceitos psicossociais 
considerados centrais para a predição de atitudes e comportamentos, inclusive para a compreensão de fenômenos de interesse de estudo das ciências sociais e humanas.

\section{METODOLOGIA}

Para atingir os objetivos propostos, foi conduzida uma pesquisa quantitativa descritiva, por meio de uma survey.

A coleta de dados contou com um questionário estruturado formado por quatro partes. A primeira contemplava questões relativas ao perfil do respondente. A segunda era relativa aos valores pessoais dos alunos, sendo que o estudo em tela utilizou o PVQ-21 (Portrait Values Questionnaire), com base no trabalho de Sambiase et al. (2014). Já a terceira englobava as questões de identificação dos fatores motivacionais individuais e ambientais, sendo as escalas obtidas do trabalho de Kopanidis (2008), que investigou o comportamento de escolha dos alunos do primeiro ano de graduação. Kopanidis (2008) utilizou a Academic Motivation Scale (AMS), um conjunto de dezessete afirmativas desenvolvido por Vallerand, Pelletier, Blais, Brières, Senécal e Vallières (1992), que mede o grau de influência de fatores motivacionais intrínsecos, extrínsecos e amotivacionais. Nessa parte foram adicionadas ainda seis questões desenvolvidas por Oliveira (2010), que buscou compreender, em seu estudo, o comportamento do consumidor de ensino superior privado a distância. As questões foram reformuladas como afirmativas para serem trabalhadas na escala Likert. A última parte do questionário contemplou as questões do Critério Brasil, desenvolvido pela ABEP (2016) para classificação socioeconômica.

A população estudada foi composta pelos 545 alunos regularmente matriculados no terceiro ano do ensino médio do município de Lagoa da Prata/MG, tanto em escolas públicas quanto em escolas particulares do município. Os dados foram coletados pessoalmente, entre os meses de março e abril de 2016, com o devido aval dos professores e das diretorias das escolas. Embora se tenha almejado a realização de um censo, a amostra inicial do estudo se restringiu aos estudantes presentes no momento da coleta, sendo, pois, composta de 406 alunos, cujo perfil socioeconômico se encontra detalhado no QUADRO 01, exposto a seguir.

No tratamento de dados foram identificados questionários com dados faltantes. O ESS (2009), citado por Sambiase et al. (2014), diz que a porcentagem aceitável de dados faltantes seria de $23,8 \%$ e a repetição de respostas de $76,2 \%$ para o PVQ-21. Foi adotado o mesmo 
parâmetro de dados faltantes $(23,8 \%)$ e assim, dos 406 questionários, 22 ultrapassaram a porcentagem aceitável de dados faltantes, resultando em uma amostra final de 384 alunos.

Quadro 1 Perfil socioeconômico dos estudantes-respondentes

\begin{tabular}{ll}
\hline \multicolumn{1}{c}{ ITEM } & \multicolumn{1}{c}{ DESCRIÇÃO } \\
\hline Faixa etária & Até 17 anos $-86,7 \%$ \\
Ocupação diária (até 17 anos) & Estudam e trabalham $-49,34 \%$ \\
Sexo & Mulheres $-53,1 \%$ \\
Classe econômica (geral) & Classe A - 12,27\% \\
& Classes B1 e B2 - 57,96\% \\
& Classes C1 e C2 $-27,42 \%$ \\
Participação por tipo de instituição de ensino & Classes D e E - 2,35\% \\
na amostra inicial & Escolas particulares -32 alunos \\
Participação por tipo de instituição de ensino & Escolas públicas -374 alunos \\
na amostra final & Escolas particulares - 32 alunos \\
& Escolas públicas - 352 alunos \\
\hline
\end{tabular}

Fonte: dados da pesquisa (2016).

O processo de tratamento dos dados se baseou em estatísticas descritivas, de frequência e testes de média, com uso do pacote estatístico SPSS 17. As etapas de análise e generalização contaram com contribuições teóricas e testes estatísticos para compreender e apontar os fatores de maior influência sobre os alunos no reconhecimento da necessidade de um ensino superior e divergências entre grupos.

\section{ANÁLISE DOS DADOS}

A análise de dados foi dividida em quatro tópicos: (1) perfil da amostra; (2) divisão dos grupos de tratamento, com a classificação dos alunos em grupos de pretensão e por natureza administrativa da instituição e com a comparação entre as classes sociais; (3) resultados relativos aos valores, com a descrição dos resultados apontados pelo PVQ-21, apresentando os valores dos alunos em geral e comparados por grupos; (4) análise dos resultados dos fatores motivacionais, com a comparação das diferenças entre os grupos. 


\subsection{PERFIL DA AMOSTRA}

A amostra apresentou o seguinte perfil: $53,1 \%$ dos alunos são do sexo feminino e 46,9\% do sexo masculino. O Portal Brasil (2015) demonstra, de acordo com dados do IBGE, que a população do ensino médio em 2010 era de 54,7\% de mulheres e 45,3\% de homens. Assim, observa-se que os dados nacionais são próximos aos obtidos na amostra. Da mesma forma, o IBGE (2014) aponta que 55,2\% de todos os jovens de 15 a 17 anos em 2012 estariam cursando o ensino médio regular. A amostra apresenta números bem acima da média nacional: $86,7 \%$ dos alunos respondentes estão dentro da idade adequada para cursar o ensino médio. Ainda segundo o IBGE (2014), os estudantes de 15 a 17 anos que estudam e trabalham seria de $19,67 \%$ e os que apenas estudam seriam $80,33 \%$. Neste item, a análise mostrou discrepância em relação aos números nacionais, pois apenas 50,66\% dos alunos do município estão apenas estudando, enquanto 49,34\% trabalham e estudam.

Quanto à questão socioeconômica, os alunos foram divididos nas seguintes classes sociais: A, B1, B2, C1, C2 e D-E, de acordo com a classificação adotada pelo Critério Brasil. Comparando-se a distribuição social dos alunos com outras realidades, percebe-se uma diferença, com a amostra tendendo a pertencer aos estratos mais elevados, quando comparada tanto com os dados do país quanto da região sudeste e de Belo Horizonte, capital do estado de Minas Gerais. Na amostra, 70,23\% dos respondentes estão nas classes A, B1 e B2, contra $30 \%$ no município de Belo Horizonte; $33 \%$ na região sudeste; e 25,8\% em nível nacional. O Conselho de Desenvolvimento Econômico e Social - CDES (2011), utilizando dados do INEP e PNAD, demonstra que a renda familiar tem influência na permanência dos jovens no ensino médio. Isso indica que os jovens de classes sociais mais baixas, em sua maioria, não estariam frequentando o ensino médio, o que ajuda a explicar os dados obtidos.

Em relação à divisão dos grupos de tratamento, ela levou em consideração a natureza administrativa da instituição de ensino (alunos de escolas públicas e privadas) e de intenção futura em relação aos estudos (ingresso ou não no ensino superior). A natureza administrativa mostrou que todos os 32 alunos da rede particular responderam aos questionários, sendo que os outros 91,7\% são provenientes da rede pública. Quanto à questão da intenção de ingresso no ensino superior, $81,5 \%$ responderam que têm pretensão de entrar no ensino superior, sendo que mais da metade dos respondentes pretende fazer isso logo após o término do ensino médio, conforme se observa na Tabela 1 a seguir. 
Tabela 1 Pretensão dos alunos em cursar o ensino superior

\begin{tabular}{|c|c|c|c|c|}
\hline Pretensão & Sigla & Frequência & Percentual & $\begin{array}{l}\% \\
\text { Cumulativo }\end{array}$ \\
\hline Sim - Imediatamente após o ensino médio & SI & 209 & 54.6 & \multirow{2}{*}{81,5} \\
\hline Sim, mas vou esperar um período de tempo & SE & 103 & 26.9 & \\
\hline Ainda não sei & NS & 56 & 14.6 & \multirow[b]{2}{*}{18,5} \\
\hline Não & $\mathbf{N}$ & 15 & 3.9 & \\
\hline
\end{tabular}

Fonte: dados da pesquisa (2016).

Dos alunos que pretendem esperar - grupo SE, 90.1\% deles não pretendem esperar mais de 2 anos do termino do ensino médio para ingressar no ensino superior.

Já a Tabela 2 demonstra a pretensão em cursar o ensino superior, por classes sociais. Verifica-se que todas as classes sociais apresentaram elevada pretensão de ingressar em um curso superior (acima de 70\%).

Tabela 2 Pretensão em cursar o ensino superior estratifica por classes sociais

\begin{tabular}{c|c|c|c|c|c|c}
\hline Pretensão & A (47) & B1 (77) & B2 (145) & C1 (71) & C2 (34) & D-E (9) \\
\hline SI & $74.47 \%$ & $54.55 \%$ & $60.69 \%$ & $38.03 \%$ & $32.35 \%$ & $66.67 \%$ \\
\hline SE & $6.38 \%$ & $24.68 \%$ & $24.83 \%$ & $32.39 \%$ & $58.82 \%$ & $22.22 \%$ \\
\hline NS & $14.89 \%$ & $18.18 \%$ & $11.03 \%$ & $22.54 \%$ & $5.88 \%$ & $11.11 \%$ \\
\hline N & $4.26 \%$ & $2.60 \%$ & $3.45 \%$ & $7.04 \%$ & $2.94 \%$ & $0.00 \%$ \\
\hline SIM (SI, SE) & $80.85 \%$ & $79.22 \%$ & $85.52 \%$ & $70.42 \%$ & $91.18 \%$ & $88.89 \%$ \\
\hline NÃO (NS, N) & $\mathbf{1 9 . 1 5 \%}$ & $\mathbf{2 0 . 7 8 \%}$ & $\mathbf{1 4 . 4 8 \%}$ & $\mathbf{2 9 . 5 8 \%}$ & $\mathbf{8 . 8 2 \%}$ & $\mathbf{1 1 . 1 1 \%}$ \\
\hline
\end{tabular}

Fonte: dados da pesquisa (2016)

Por meio da Tabela 2, observa-se que a classe C1 apresentou a menor pretensão de ingressar no ensino superior. $\mathrm{Na}$ análise, $70,42 \%$ dos alunos da classe $\mathrm{C} 1$ indicaram que querem cursar o ensino superior, sendo que 38,03\% responderam "Sim, imediatamente" e 32,39\% “Sim, mas vou esperar". As classes A e C2 foram as únicas que não apresentaram um comportamento gradativo. Apenas 6,38\% dos alunos da classe A indicaram que pretendem esperar, enquanto na classe C2 foram mais da metade dos alunos (58,82\%). A pesquisa também apontou que, dos 9 alunos que pertencem às classes D-E, nenhum respondeu que não tem intenção de entrar no ensino superior. 


\subsection{VALORES}

Conforme asseveram Sambiase et al. (2014), Universalismo representa a preocupação com o bem-estar de todas as pessoas do mundo e Benevolência com o bem-estar das pessoas próximas, sendo que ambos os valores integram a dimensão da Autotranscendência. Nesse sentido, observou-se, na amostra, fortes traços de Universalismo e Benevolência e fracos indícios de Poder, conforme se observa na Tabela 3 a seguir:

Tabela 3 Valores em ordem decrescente de média

\begin{tabular}{l|c|c}
\hline \multicolumn{1}{c|}{ Afirmativas - PVQ21 } & Média & $\begin{array}{c}\text { D. } \\
\text { Padrão }\end{array}$ \\
\hline Universalismo 1 - Justiça social, Igualdade & 4.74 & 0.67 \\
\hline Universalismo 3 - Proteção ao meio ambiente & 4.66 & 0.61 \\
\hline Benevolência 2 - Leal, Dedicado aos seus amigos & 4.62 & 0.68 \\
\hline Segurança 1 - Viver em um ambiente seguro & 4.54 & 0.77 \\
\hline Segurança 2 - Segurança nacional & 4.51 & 0.78 \\
\hline Universalismo 2 - Mente aberta & 4.51 & 0.79 \\
\hline Benevolência 1 - Ajuda as pessoas próximas & 4.45 & 0.70 \\
\hline Autodeterminação 2 - Liberdade, Escolhe os próprios objetivos & 4.41 & 0.83 \\
\hline Realização 1 - Demonstrar habilidades, Ser admirado & 4.40 & 0.85 \\
\hline Realização 2 - Bem sucedido, Ter reconhecimento & 4.39 & 0.86 \\
\hline Tradição 1 - Humilde, Modesto & 4.39 & 0.83 \\
\hline Estimulação 1 - Variação na vida, Gosta de surpresas & 4.39 & 0.80 \\
\hline Hedonismo 2 - Se divertir, Curte a vida, Prazer & 4.36 & 0.89 \\
\hline Autodeterminação 1 - Criatividade, Originalidade & 4.35 & 0.83 \\
\hline Conformidade 1 - Obediente, Autodisciplina & 3.68 & 1.25 \\
\hline Conformidade 2 - Comportar adequadamente & 3.67 & 1.20 \\
\hline Tradição 2 - Respeita a tradição, Devoto & 3.63 & 1.27 \\
\hline Hedonismo 1 - Aproveitar os prazeres da vida & 3.58 & 1.25 \\
\hline Estimulação 2 - Aventureiro, Correr riscos & 3.34 & 1.26 \\
\hline Poder 2 - Reconhecimento social, Autoridade & 3.15 & 1.26 \\
\hline Poder 1 - Riqueza & $\mathbf{2 . 9 3}$ & $\mathbf{1 . 3 2}$ \\
\hline
\end{tabular}

Fonte: dados da pesquisa (2016).

Os valores de Segurança, Autodeterminação e Realização também atuam fortemente no comportamento dos alunos. De acordo com Blackwell et al. (2005), o valor Segurança busca harmonia e estabilidade individual; a Autodeterminação, liberdade, livre escolha e criatividade; e a Realização, sucesso pessoal e reconhecimento social.

Assim, os valores dos alunos indicam que eles procuram escolher os próprios objetivos, se preocupam com estabilidade individual, o sucesso pessoal, o bem-estar da sociedade e dos grupos em que convivem. O Gráfico 1 destaca a estrutura dos valores do 
alunos por dimensões de valores, demonstrando a dimensão da autotranscendência como a que mais exerce influência nos alunos:

Gráfico 1 Estrutura dos Valores dos alunos

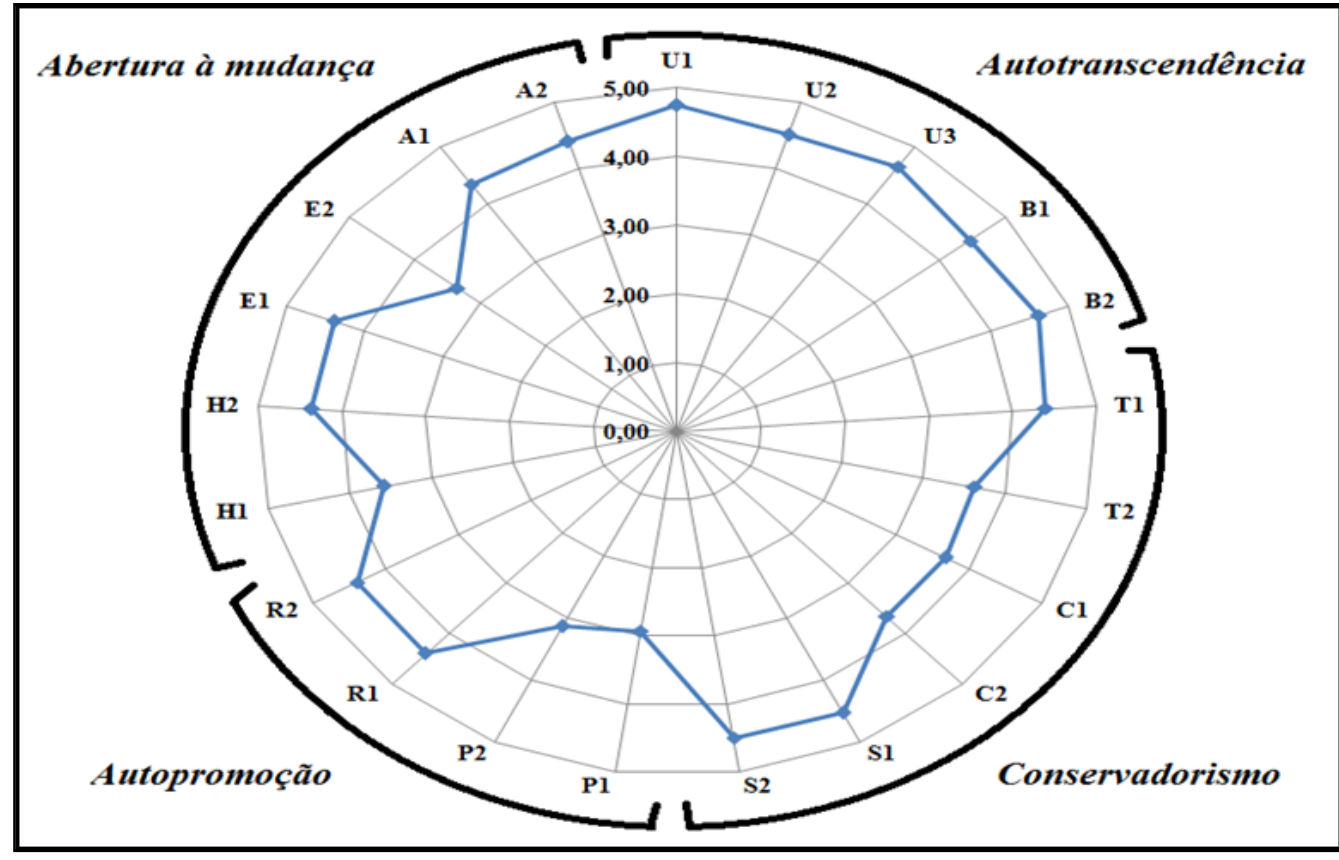

Fonte: dados da pesquisa (2016).

Cumpre ressaltar que, de acordo com Torres, Schwartz e Nascimento (2015), para melhor avaliar a teoria, é importante determinar se cada valor se relaciona significativamente com os comportamentos que esperam motivar. Segundo a teoria de valores, as associações entre os valores e o comportamento devem refletir um contínuo circular motivacional. Os valores são compatíveis à medida que os comportamentos promovem ou expressam metas de um par de valores. Quando os comportamentos têm consequências opostas para dois valores, promovendo a meta de um em detrimento do outro, os valores estão em conflito.

O Gráfico 1 e a Tabela 3 permite avaliar o comportamento do contínuo motivacional dos alunos. Pode-se verificar que o valor poder possui a menor dentre as médias dos valores, enquanto os valores da dimensão da autotranscendência, que refletem o pensamento social, estão dentre as maiores médias entre os valores.

Para verificar se alunos de escolas públicas e privadas apresentam diferenças em relação aos valores, assim como aqueles com diferentes pretensões em relação ao ensino superior, optou-se por realizar análises comparativas entre os alunos por natureza 
administrativa da escola e por grupos com diferentes pretensões de ingressar no ensino superior.

A Tabela 4 demonstra os valores que apresentaram disparidade entre estudantes por natureza administrativa:

Tabela 4 Comparação dos Valores entre natureza administrativa

\begin{tabular}{l|l|c|c|l}
\hline Valores & Instituição & Média & Desvio Padrão & Teste -t \\
\hline *Realização 1 - Demonstrar & Privada & $4.06^{*}$ & 0.84 & $\mathrm{p}=0.0217^{*}$ \\
habilidades, Ser admirado & Publica & $4.43^{*}$ & 0.85 & \\
\hline *Universalismo 2- Mente & Privada & $4.78^{*}$ & 0.49 & $\mathrm{p}=0.00346^{*}$ \\
aberta & Publica & $4.48^{*}$ & 0.81 & \\
\hline *Conformidade & Privada & $3.06^{*}$ & 1.53 & $\mathrm{p}=0.0214^{*}$ \\
$\begin{array}{l}\text { Obediente, } \\
\text { Autodisciplina }\end{array}$ & Publica & $3.73^{*}$ & 1.21 & \\
\hline *Conformidade 2 - & Privada & $2.94^{*}$ & 1.19 & $\mathrm{p}=0.001^{*}$ \\
Comportar adequadamente & Publica & $3.73^{*}$ & 1.18 & \\
\hline *Tradição 1 - Humilde, & Privada & $4.00^{*}$ & 0.95 & $\mathrm{p}=0.0196^{*}$ \\
Modesto & Publica & $4.42^{*}$ & 0.81 & \\
\hline *Tradição 2 - Respeita a \\
tradição, Devoto & Privada & $\mathbf{2 . 4 4 *}$ & $\mathbf{1 . 2 9}$ & $\mathbf{p}=\mathbf{0 . 0 0 1 *}$ \\
\hline
\end{tabular}

Fonte: dados da pesquisa. *Apresentaram diferença estatisticamente significativa ao nível de 0.05 .

Como é possível constatar na Tabela 4, apenas um dos valores demonstrou influenciar mais os alunos das escolas privadas, sendo este o Universalismo 2 - mente aberta. Os demais valores se demonstraram mais influentes nos alunos de instituições públicas.

Dentre os valores que apresentaram disparidade entre os grupos, quatro dos seis integram a dimensão do Conservadorismo, portanto, os alunos das instituições privadas são menos conservadores, não restringindo suas ações e possuindo baixa influência dos valores obediência e autodisciplina. O Gráfico 2 apresenta a comparação entre os grupos de natureza administrativa e a disparidade descrita na análise da Tabela 3:

$\mathrm{Na}$ comparação dos valores entre os grupos de pretensão ocorreram diferenças estatisticamente significativas apenas em duas afirmativas. A Tabela 5 a seguir apresenta essas afirmativas.

A Tabela 5 indica que os alunos que manifestaram o desejo de ingressar no ensino superior apresentaram índice maior de Universalismo 2 - mente aberta do que aqueles que se mostraram indecisos quanto a essa decisão. A Tabela 5 apontou também que os alunos que pretendem esperar possuem uma média menor no valor Hedonismo 1 - aproveitar os prazeres 
da vida, se comparados aos alunos que pretendem ingressar no ensino superior imediatamente após o termino do ensino médio.

Quadro 2 Escala dos Valores entre os grupos de natureza administrativa

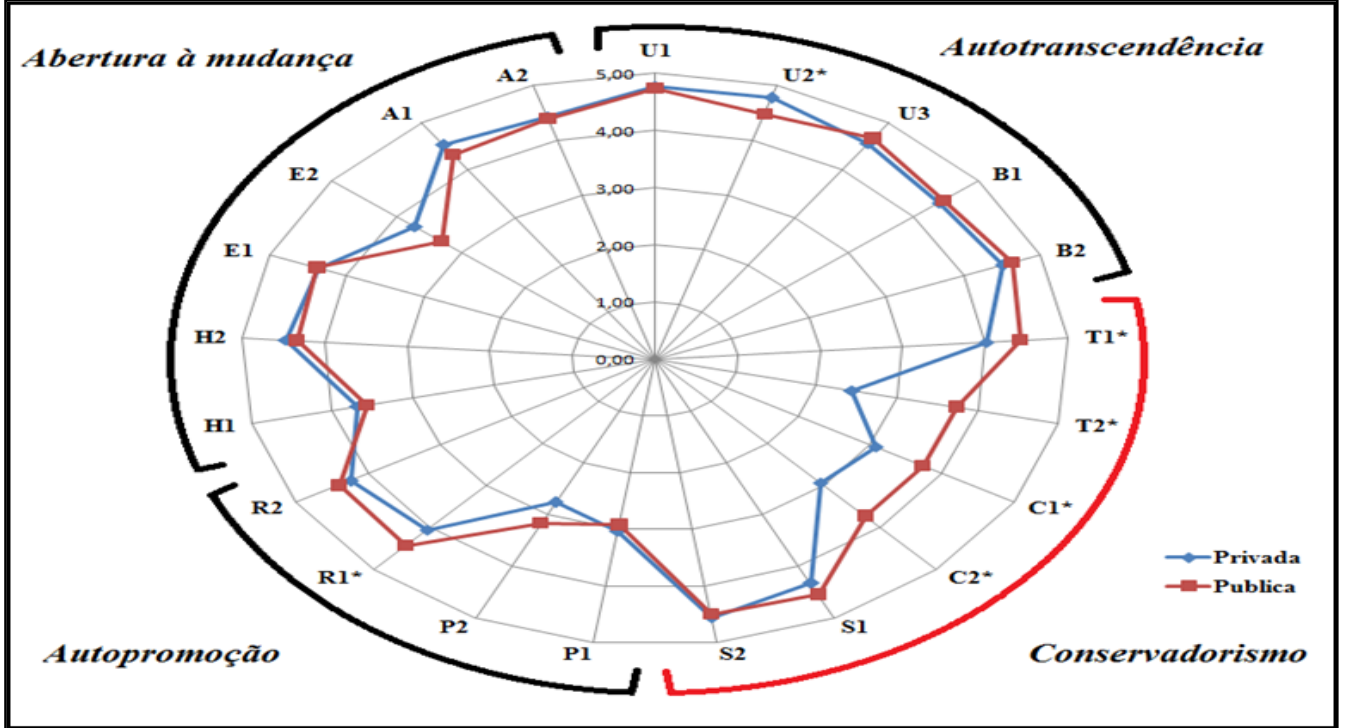

Fonte: Dados da pesquisa (2016).

Tabela 5 Comparação dos Valores entre os grupos de pretensão

\begin{tabular}{l|l|l|l|l}
\hline \multicolumn{1}{c|}{ Valores } & Pretensão & Média & Desvio Padrão & ANOVA \\
\hline *Hedonismo 1 - Aproveitar & SI* & $3.71^{*}$ & 1.21 & \\
os prazeres da vida & SE* & $3.26^{*}$ & 1.34 & $\mathrm{~F}=3.299$ \\
& NS & 3.71 & 1.16 & $\mathrm{p}=0.02^{*}$ \\
& $\mathrm{~N}$ & 3.47 & 1.25 & \\
\hline *Universalismo 2 - Mente & SI* & $\mathbf{4 . 6 1 *}$ & $\mathbf{0 . 6 9}$ & \\
aberta & SE & $\mathbf{4 . 4 9}$ & $\mathbf{0 . 8 6}$ & $\mathbf{F}=\mathbf{4 . 4 5 3}$ \\
& NS* & $\mathbf{4 . 1 8 *}$ & $\mathbf{0 . 9 6}$ & $\mathbf{p}=\mathbf{0 . 0 0 4 *}$ \\
& N & $\mathbf{4 . 4 7}$ & $\mathbf{0 . 8 3}$ & \\
\hline
\end{tabular}

Fonte: dados da pesquisa. *Apresentaram diferença estatisticamente significativa ao nível de 0.05

O Gráfico 3 a seguir apresenta as médias dos valores motivacionais por grupos de pretensão. 
Gráfico 3 Estrutura de Valores por grupos de pretensão

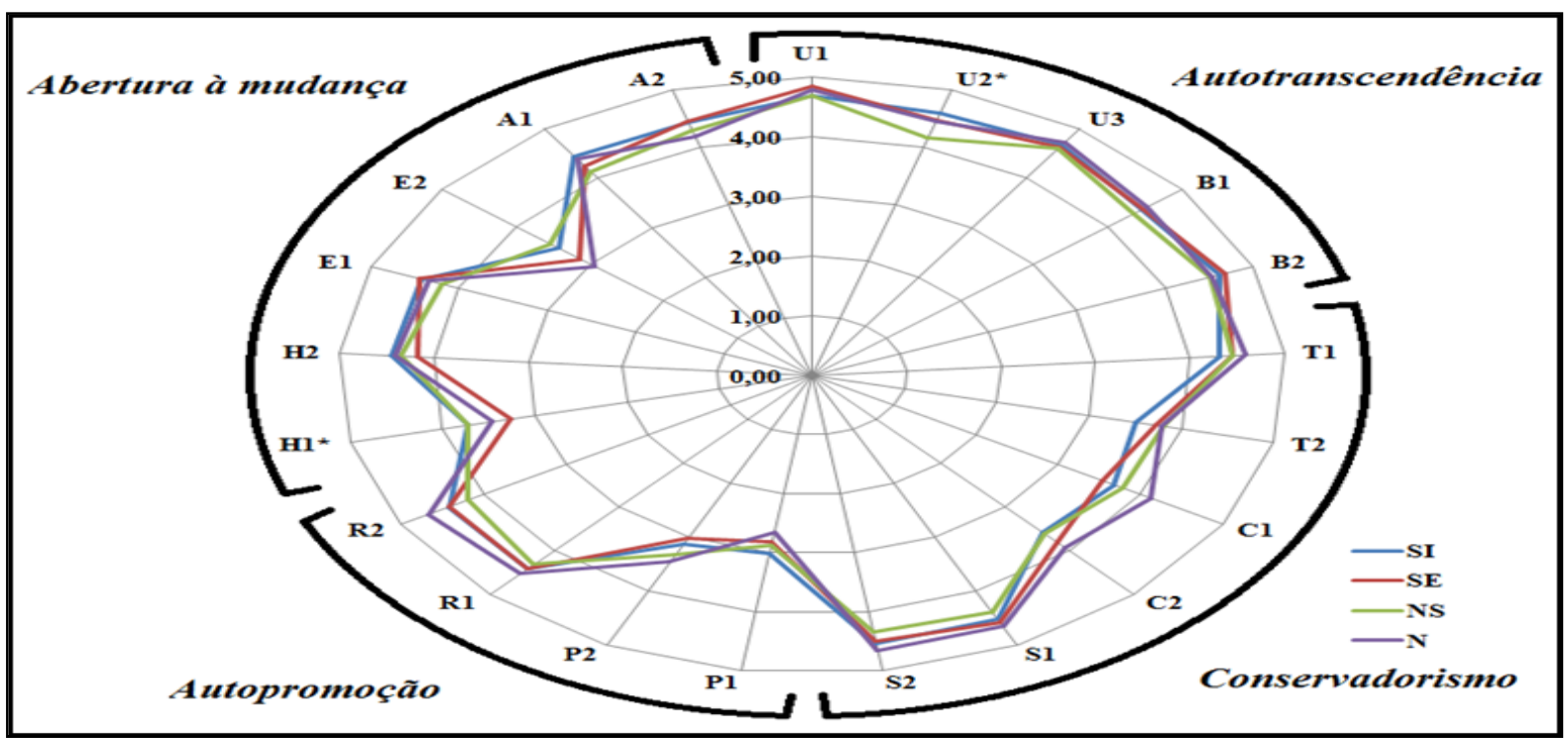

Fonte: dados da pesquisa (2016).

Observa-se que os alunos, independente da divisão por grupos de pretensão, possuem valores semelhantes e apresentam valores predominantes da dimensão de Autotranscendência.

\subsection{FATORES MOTIVACIONAIS}

Em relação aos fatores motivacionais, constatou-se que os mais importantes para os alunos foram de caráter intrínseco e extrínseco, em detrimento aos amotivacionais, mostrando, assim, que os alunos sofrem influência motivacional tanto externa quanto internamente no reconhecimento da necessidade de cursar o ensino superior. Holmes et al. (2011), citados por Silva (2013), dizem que os valores podem ser categorizados como extrínsecos e intrínsecos. $\mathrm{Na}$ análise do autor, os valores extrínsecos estariam centrados na aprovação externa ou em recompensas, enquanto que os intrínsecos estariam relacionados à atividades internamente gratificantes. Vallerand et al. (1992) lembram que os valores amotivacionais são impessoais, não partindo, pois, do individuo. Os resultados relativos aos fatores motivacionais para se cursar o ensino superior podem ser observados na Tabela 6.

Conforme se observa na Tabela 6 , os fatores motivacionais intrínsecos que mais influenciam os alunos são a busca por informações e conhecimento, retratando a necessidade cognitiva de conhecer e de ajudar os outros a realizar seu potencial; necessidade que é natural do ser humano, por sua busca do sentido das coisas, de forma a organizar o mundo em que vive. 


\section{INTENÇÃO EM INGRESSAR NO ENSINO SUPERIOR: UMA ANÁLISE SOB A PERSPECTIVA DOS VALORES E DOS FATORES MOTIVACIONAIS \\ DOI: http://dx.doi.org/10.5007/1983-4535.2018v11n3p122}

Tabela 6 Fatores motivacionais em ordem decrescente de média

\begin{tabular}{|c|c|c|c|c|}
\hline Afirmativa & Motivação & Lócus & $\begin{array}{c}\text { Médi } \\
\text { a }\end{array}$ & $\begin{array}{c}\text { D. } \\
\text { Padrão }\end{array}$ \\
\hline Buscar informações, necessidade cognitiva & Intrínseca & Interno & 4.81 & 0.52 \\
\hline $\begin{array}{lll}\begin{array}{l}\text { Auxiliar nas } \\
\text { desempenhadas }\end{array} & \text { atividades } & \text { profissionais } \\
\end{array}$ & Extrínseca & Externo & 4.73 & 0.55 \\
\hline Aprender novas coisas, necessidade cognitiva & Intrínseca & Interno & 4.72 & 0.61 \\
\hline Proporcionar um avanço na vida & Extrínseca & Externo & 4.58 & 0.77 \\
\hline Conseguir o trabalho que quero & Extrínseca & Externo & 4.56 & 0.75 \\
\hline Um diploma é importante para mim & Extrínseca & Interno & 4.54 & 0.77 \\
\hline Ter o desejo de cursar o ensino superior & Intrínseca & Interno & 4.47 & 0.81 \\
\hline Para seguir a carreira que escolhi & Extrínseca & $\begin{array}{l}\text { Algo } \\
\text { Interno }\end{array}$ & 4.44 & 0.92 \\
\hline $\begin{array}{l}\text { Assegurar um emprego rentável, ajudar na } \\
\text { despesa }\end{array}$ & Extrínseca & Externo & 4.43 & 0.87 \\
\hline Conseguir um emprego de prestígio & Extrínseca & $\begin{array}{l}\text { Algo } \\
\text { Interno }\end{array}$ & 4.37 & 0.80 \\
\hline Para me tornar uma pessoa mais educada & Intrínseca & Interno & 4.36 & 0.86 \\
\hline Conhecer e fazer novos amigos & $\begin{array}{l}\text { Amotivacion } \\
\text { al }\end{array}$ & Impessoal & 4.31 & 0.86 \\
\hline Aproveitar o desafio acadêmico do curso & Intrínseca & Interno & 4.14 & 0.88 \\
\hline Meus pais querem que eu vá para universidade & $\begin{array}{l}\text { Amotivacion } \\
\text { al }\end{array}$ & Impessoal & 4.05 & 1.25 \\
\hline Melhorar meu posicionamento na sociedade & Extrínseca & Externo & 4.00 & 1.09 \\
\hline Permitirá que eu ganhe mais dinheiro & Extrínseca & Externo & 3.99 & 0.97 \\
\hline $\begin{array}{l}\begin{array}{l}\text { Experimentar a vida } \\
\text { independente }\end{array} \\
\text { de estudante, ser }\end{array}$ & Intrínseca & Interno & 3.88 & 1.20 \\
\hline $\begin{array}{l}\text { Mostrar que posso ser bem-sucedido na } \\
\text { universidade }\end{array}$ & Extrínseca & $\begin{array}{l}\text { Algo } \\
\text { Externo }\end{array}$ & 3.87 & 1.17 \\
\hline $\begin{array}{l}\text { Hoje em dia todo mundo tem que ter um } \\
\text { diploma }\end{array}$ & $\begin{array}{l}\text { Amotivacion } \\
\text { al }\end{array}$ & Impessoal & 3.48 & 1.38 \\
\hline Frequentar a universidade expressa quem eu sou & Extrínseca & Interno & 3.39 & 1.22 \\
\hline Porque todos os meus amigos estão indo & $\begin{array}{l}\text { Amotivacion } \\
\text { al }\end{array}$ & Impessoal & 2.50 & 1.34 \\
\hline
\end{tabular}

Fonte: dados da pesquisa (2016).

Já em relação aos fatores motivacionais extrínsecos, os que mais influenciaram os alunos foram todos de lócus externo: "auxiliar nas atividades profissionais desempenhadas", "conseguir o trabalho que quero" e "proporcionar um avanço na vida". Estes fatores remetem à realização profissional e pessoal, podendo ser vinculados aos valores dos alunos. Como já identificado, eles sofrem forte influência do valor de Realização, buscando ser bemsucedidos, ter a admiração e o reconhecimento das pessoas.

Embora não tenham impacto forte sobre a pretensão dos respondentes em ingressar no ensino superior, os fatores amotivacionais apresentaram resultados interessantes: as duas afirmativas que obtiveram maiores médias ("Conhecer e fazer novos amigos"; e "Meus pais 
querem que eu vá para universidade") indicam que os alunos sofrem influência externa da família e dos grupos de aspiração na atitude de cursar o ensino superior. Outro resultado interessante, mas em sentido oposto, é a indicação de que os grupos sociais dos quais os estudantes participam não influenciam, de maneira sólida, a decisão deles em adentrar o ensino de terceiro grau. Vale ressaltar, aqui, a discrepância deste resultado em relação às pesquisas feitas por Torres e Perez-Nebra (2007) e por Torres e Allen (2009) nas quais, estudando comparativamente as culturas brasileira e australiana, concluíram que, no Brasil, há um sentimento de coletivismo muito forte, ou seja, há uma predominância a se deixar levar pela influência do grupo social a que se pertence, em detrimento à decisão individualizada, mais presente na população australiana. Por fim, é importante lembrar o que ensinam Vallerand et al. (1992), ao ponderarem que o indivíduo que possui forte influência dos fatores amotivacionais acaba por abandonar a faculdade, caso venha a nela ingressar.

Analisando os fatores motivacionais por natureza administrativa foram identificadas três afirmativas que possuem divergência em função das intuições serem privadas ou públicas, conforme dados da Tabela 7.

Tabela 7 Comparação dos fatores motivacionais entre natureza administrativa

\begin{tabular}{|c|c|c|c|c|c|}
\hline Afirmativa & Motivação & Instituição & Média & D. P. & Teste -t \\
\hline \multirow{3}{*}{$\begin{array}{l}\text { d. Porque todos os meus amigos } \\
\text { estão indo }\end{array}$} & \multirow{3}{*}{ Amotiva. } & Privada & 1.78 & 1.07 & \multirow{3}{*}{$\mathrm{p}=0.001^{*}$} \\
\hline & & Publica & 2.58 & 1.35 & \\
\hline & & Ambas & 2.50 & 1.34 & \\
\hline \multirow{3}{*}{$\begin{array}{l}\text { i. Mostrar que posso ser bem- } \\
\text { sucedido na universidade }\end{array}$} & \multirow{3}{*}{ Extrínseca } & Privada & 3.28 & 1.44 & \multirow{3}{*}{$\mathrm{p}=0.0184^{*}$} \\
\hline & & Publica & 3.93 & 1.12 & \\
\hline & & Ambas & 3.87 & 1.17 & \\
\hline \multirow{3}{*}{$\begin{array}{l}\text { p. Hoje em dia todo mundo tem } \\
\text { que ter um diploma }\end{array}$} & \multirow{3}{*}{ Amotiva. } & Privada & 2.66 & 1.47 & \multirow{3}{*}{$\begin{array}{l}\mathbf{p}_{0.00171 *}= \\
\end{array}$} \\
\hline & & Publica & 3.58 & 1.34 & \\
\hline & & Ambas & 3.48 & 1.38 & \\
\hline
\end{tabular}

Fonte: dados da pesquisa. *Apresentaram diferença estatisticamente significativa ao nível de 0.05 .

Observa-se, por meio da Tabela 7, que em todos os três casos os alunos das instituições privadas apresentaram médias menores em comparação com os alunos das instituições públicas. As três motivações em relação a ingressar no ensino superior: "porque todos os meus amigos estão indo"; "para mostrar que posso ser bem sucedido na universidade"; e "porque hoje em dia todo mundo tem que ter um diploma" - estão entre as quatro que apresentaram as menores médias dos influenciadores motivacionais. Mesmo com as diferenças significativas, as médias permaneceram abaixo dos 4 pontos, indicando baixa influencia dessas afirmações em ambos os grupos. 


\section{CONCLUSÃO}

Esse trabalhou procurou analisar os fatores que influenciam os alunos do ensino médio no reconhecimento da necessidade de cursar o ensino superior. Nesse sentido, constatou que os alunos sofrem forte influência de fatores intrínsecos, como a busca por informações, conhecimento e aprendizado. Tais fatores estariam vinculados à necessidade cognitiva e todos são de regulação interna.

Apontou-se, também, que os alunos sofrem influência de fatores extrínsecos, como a busca por realização pessoal, profissional e desejo de avançar na vida, sendo todos de regulação externa. Esses fatores extrínsecos demonstram que o valor de Realização dos alunos estaria influenciando na decisão de cursar o ensino superior.

Os valores também demonstraram influenciar os alunos. Eles apresentaram características de autotranscendência, que integra os valores de universalismo e benevolência. Isso demonstra que os alunos tomam suas atitudes pensando no bem-estar das pessoas próximas e distantes. Três outros valores indicaram exercer grande influência nas atitudes dos alunos, sendo eles: Realização, Segurança e Autodeterminação. A Segurança busca harmonia e estabilidade individual; a Autodeterminação, liberdade, livre escolha e criatividade; e a Realização, sucesso pessoal e reconhecimento social. O resultado do estudo também apontou que o valor menos influente nos alunos seria o Poder, que tem como valores exemplares riqueza e autoridade. Observou-se ainda que, no comparativo dos grupos dos alunos que pretendem e os que não pretendem ingressar no ensino superior, os valores permaneceram similares.

$\mathrm{Na}$ comparação entre alunos das instituições públicas e das instituições privadas, ocorreram diferenças estatisticamente significativas. Os alunos das escolas privadas possuem traços mais fracos de conservadorismo, sendo menos conservadores e tradicionais, se opondo menos a mudanças e possuindo baixa influência dos valores exemplares de obediência e autodisciplina. Outra diferenciação significativa dos alunos de escolas privadas é que eles sofrem menos influência dos fatores amotivacionais. Isso indica que eles tendem a não desistir do ensino superior após ingressarem.

$\mathrm{Na}$ análise de quantos alunos pretendem ingressar no ensino superior o número foi bem expressivo: 312 dos 383, ou seja, $81,5 \%$ dos alunos têm pretensão de entrar no ensino superior, enquanto que 56 não sabem ainda e apenas 15 afirmaram que não querem, sendo que todos os alunos das instituições privadas indicaram pretensão em entrar no ensino superior. 
A situação econômica dos alunos é outro fator que influencia na pretensão de cursar o ensino superior. Poucos alunos da classe A indicaram que pretendem esperar, em comparação às demais classes sociais. Já a classe $\mathrm{C} 2$ indicou ter maior pretensão de esperar. A classe C1 foi, dentre as classes, a que possui menor pretensão de ingressar no ensino superior.

Espera-se que esses resultados possam contribuir para uma melhor compreensão desse público potencial, tanto pelas IES quanto pelo Poder Público. A uma, que o presente estudo possa auxiliar as IES a elaborar estratégias condizentes com as necessidades, motivações, valores e perfil socioeconômico desse público alvo. A duas, da mesma forma, que o Poder Público atente para a necessidade de implementação de políticas públicas que robusteçam o ensino superior brasileiro, de modo a que nele os jovens tenham uma verdadeira alternativa de progresso tanto de cunho econômico e social quanto em termos do desenvolvimento de sua cidadania.

\section{REFERÊNCIAS}

ASSOCIAÇÃO BRASILEIRA DE EMPRESAS DE PESQUISA. Critério Brasil 2015 e atualização da distribuição de classes para 2016. ABEP, 2016. Disponível em $<$ http://www.abep.org/criterio-brasil $>$. Acesso em: 20 fev. 2016.

BLACKWELL, Roger D; MINIARD, Paul W; ENGEL, James F. Comportamento do Consumidor. 9.ed. São Paulo: Pioneira Thomson Learning, 2005.

BRUNER, Gordon C.; POMAZAL, Richard J. Problem recognition: the crucial first stage of the consumer decision process. Journal of Consumer Marketing, v. 5, n. 1, p. 53-63, 1988.

CALVOSA, Marcelo Vinícius Doria. Uma pesquisa bibliométrica sobre valores pessoais: a análise global de instrumentos de mensuração de valores pessoais. In: SIMPÓSIO DE GESTÃO DA INOVAÇÃO TECNOLÓGICA, 28, 2012, Salvador. Anpad, Salvador, 2012. Disponível em:

$<$ http://www.anpad.org.br/diversos/trabalhos/Simp\%C3\%B3sio/simposio_2012/2012_SIMPO SIO54.pdf>. Acesso em 09 jul.2016.

CASTRO, Pedro; CALVOSA, Marcello; WRIGHT, J.; CASADO, T. Prioridades Axiológicas e Expectativa de Sucesso: um Estudo com os CEO S do Futuro. In: Encontro Científico da ANPAD - EnANPAD 2009, 2009, São Paulo. Anais do XXXIII EnANPAD. São Paulo, 2009.

FLETCHER, Keith. An Investigation into the nature of problem recognition and deliberation in buyer behaviour. European Journal of Marketing, v. 22, n. 5, p. 58-66, 1988.

GIGLIO, Ernesto. O comportamento do Consumidor. 2.ed. São Paulo: Pioneira Thomson Learning, 2003. 
HOLMES, T.; BLACKMORE, E.; HAWKINS, R.; WAKEFORD, T. The common cause handbook. PIRC - Public Interest Research Centre, Reino Unido, 2011.

INSTITUTO NACIONAL DE ESTUDOS E PESQUISAS EDUCACIONAIS. Sinopses Estatísticas da Educação Superior - Graduação. INEP, Brasília, 2015. Disponível em: $<$ http://portal.inep.gov.br/superior-censosuperior-sinopse> . Acesso em: 15 abr. 2016.

KARSAKLIAN, Elaine. Comportamento do Consumidor. 1.ed. São Paulo: Atlas, 2000.

KOPANIDIS, Foula Zografina. An investigation of undergraduate choice behaviour of a preferred program, discipline and university: a conceptual model. Tese de Doutorado. Royal Melbourne Institute of Technology, 2008. Disponível em: $<$ https://researchbank.rmit.edu.au/eserv/rmit:6153/Kopanidis.pdf $>$. Acesso em: 20 jun. 2015

KOTLER, Philip; KELLER, Kevin Lane. Administração de marketing. 12.ed. São Paulo: Pearson Prentice Hall, 2006.

MARTINS, Antonio Carlos Pereira. Ensino superior no Brasil: da descoberta aos dias atuais. In: Acta Cirúrgica Brasileira, Vol. 17, São Paulo, 2002. Disponível em: $<$ http://www.scielo.br/scielo.php?script=sci arttext\&pid=S0102-86502002000900001 $>$. Acesso em: 05 jun. 2015.

OLIVEIRA, Luciana Nery de. Comportamento do consumidor de educação superior a distância: análise das características influenciadoras e do processo de compra numa instituição baiana de ensino superior privado. Dissertação (Mestrado) - Universidade Federal da Bahia, 2010. Disponível em: $<$ https://repositorio.ufba.br/ri/handle/ri/7652 $>$. Acesso em: 15 mar. 2016

ROCCAS, S.; SCHWARTZ, Shalom. H.; AMIT, A. Personal Value Priorities and National Identification. Political Psychology, v. 31, n. 3, June 2010, p. 393-419.

ROKEACH, Milton. The nature of human values. Free press, 1973.

SAMBIASE, Marta Fabiano; TEIXEIRA, Maria Luisa Mendes; BILSKY, Wolfgang; ARAUJO, Bruno Felix Von Borell de; DOMENICO, Silvia Marcia Russi De. Confrontando estruturas de valores: um estudo comparativo entre PVQ-40 e PVQ-21. Psychology, v. 27, n. 4, p. 728-739, 2014.

SCHWARTZ, Shalom H. Universals in the content and structure of values: Theory ad empirical tests in 20 countries. U M. Zanna. Advances in experimental social psychology, 1992.

SCHWARTZ, Shalom H. Studying values: Personal adventure, future directions. Journal of Cross-Cultural Psychology, v. 42, n. 2, p. 307-319, 2011.

SÉCCA, Rodrigo Ximenes; SOUZA, Rodrigo Mendes Leal de. Análise do setor de ensino superior privado no Brasil. BNDES Setorial, Rio de Janeiro, n. 30, p. 103-156, 2009. 
SILVA, Virgínia Sebastião da. Segmentação baseada em valores pessoais: um estudo com consumidores de alimentos orgânicos. Dissertação (Mestrado) - Universidade Federal do Rio Grande do Sul, escola de Administração, Porto Alegre, 2013. Disponível em: $<$ https://www.lume.ufrgs.br/bitstream/handle/10183/777444/000897464.pdf? sequence=1 $>$. Acesso em 15 abr. 2016.

TAMAYO, Alvaro. Hierarquia de valores transculturais e brasileiros. Psicologia: teoria e pesquisa, v. 23, n. Special, p. 7-15, 2007.

TAMAYO, Álvaro e SCHWARTZ, Shalom H. Estrutura motivacional dos valores humanos. . Psicologia: Teoria e Pesquisa, Brasília, v. 9, n. 2, p. 329-348, 1993.

TINOCO, João Eduardo; ASSÊNCIO, E.; JOÃO, B.; CLARO, J. Influência dos Valores Individuais no Desempenho Empresarial: um estudo usando o inventário de valores de Schwartz. In: SEMEAD, 13 - Seminários em Administração. São Paulo. SEMEAD, 2010.

TORRES, Cláudio Vaz e PÉREZ-NEBRA, Amália Raquel. The influence of human values on Holiday destination choice in Australia and Brazil. BAR - Brazilian Administration Review, v. 4, n.3, art. 5, p. 63-76, sept/dec. 2007.

TORRES, Cláudio Vaz e ALLEN, Michael W. Valores humanos e escolha do consumidor na Austrália e Brasil. Psicologia: Teoria e Pesquisa, Brasília, v. 25, n. 4, p. 611-620, Out-Dez, 2009.

TORRES, Cláudio V., SCHWARTZ, Shalom H.; NASCIMENTO, Thiago G. A Teoria de Valores Refinada: associações com comportamento e evidências de validade discriminante e preditiva. Revista Psicologia USP, 2015.

VALLERAND, Robert J.; PELLETIER, L.; BLAIS, M. R.; BRIÈRES, N. M.; SENÉCAL, C.; e VALLIÈRES, E. F. The Academic Motivation Scale: A measure of intrinsic, extrinsic, and amotivation in education. Educational and psychological measurement, v. 52, n. 4, p. 1003-1017, 1992. 